\title{
ANALYSIS OF SHADING DEVICES IMPACT ON BUILDING ENVELOPE. CASE STUDY
}

loana Udrea ${ }^{1}$, Viorel Ion Patroescu², Mihaela-Stela Georgescu³ ${ }^{3}$, Romeo-Traian Popa ${ }^{4}$

${ }^{1}$ ASC-Romania, 9 Stefan Marinescu Street, District 6, 060121, Bucharest, Romania, e-mail: ioana.udrea@asc-ro.com;

2INCD ECOIND, 71-73 Drumul Podu Dambovitei, District 6, 060042, Bucharest, Romania, 060652, email: tehnologi@incdecoind.ro;

3"Ion Mincu" University of Architecture and Urbanism, 18-20 Academiei Street, District 1, 010014 Bucharest, Romania, e-mail: mihaelastela.georgescu@yahoo.com; ${ }^{4}$ University POLITEHNICA of Bucharest, Faculty of Mechanical Engineering and Mechatronics, Thermodynamics Department, 313 Spl. Independentei, District 6, 060042, Bucharest, Romania, e-mail: poparomeo@gmail.com.

\begin{abstract}
2010 Energy Performance of Buildings Directive and 2012 Energy Efficiency Directive require a continued reduction of energy consumption in buildings. Although consumption minimization methods are generally available, country-specific aspects have to be analyzed for different climates. In Romania, the climate is temperate (Köppen climate - type D) and it is characterized by extreme temperatures with hot summers and cold winters. Although heating consumption represents the principal component of the total energy consumption, special attention should be paid to the cooling consumption in this kind of climate. Summer shading devices impact on building envelope is studied in this paper. For this purpose, an office building with curtain walls, located in Bucharest, was chosen. The curtain wall on South façade is shaded with an exterior blades metallic system. The behavior of the glazed shaded area was analyzed in summer time, even for a bigger period, between the spring equinox and the autumn one. Three significant days were chosen for this purpose and the shaded area was computed hour by hour for each day. At the end, the cooling energy load decreasing realized by the shading devices was determined. Also, the optimal distance between two blades was calculated, in terms of energy efficiency.
\end{abstract}

Keywords: cooling energy load, curtain walls, metallic blades, Romanian climate, shading device

\section{Introduction}

EU's main legislation when it comes to reducing the energy consumption of buildings is represented by 2010 Energy Performance of Buildings Directive [1] and 2012 Energy Efficiency Directive [2]. Buildings represent $40 \%$ of the Union's final energy consumption and are crucial to achieving the Union objective of reducing greenhouse gas emissions by $80-95 \%$ by 2050, as compared to 1990 .

Overheating risk in summer is increased when glass facades are used. In [5] the authors remark that nowadays, curtain wall is the norm, due to which there is an increase in direct solar gain and heat loss through the window inside the building, causing massive thermal load. In [3] the authors explain that the cooling demand rises 
significantly in buildings with curtain walls and it depends on the climate changes. Use of blinds has been one of the best measures for this problem.

According to Köppen classification [5], Romanian climate is climate type D - temperate continental. This kind of climate is characterized by cold winters and hot summers. The cooling consumption and the overheating risk in Romanian climate are very important $[6,7]$, although the highest percentage of building consumption is generated by the heating in this climate. The shading devices may be considered as interesting solutions to improve thermal comfort and to reduce the cooling consumption in summer in Romania, especially for buildings with glass facades.

For this purpose, an office building with curtain walls, was chosen. The South facade of the building is a glazing one and it is shaded with an exterior blades metallic system. The optimal distance in terms of building shading for mounting two blades was calculated. The decreasing of the cooling energy load caused by the shading device was determined.

\section{Methods and Procedure}

\section{a. Building description}

INCD-ECOIND is the building of a research institute, in the chemical field, and it is located in the North-West side of Bucharest, Romania. It is an office and laboratory building and the construction year is 2011 . The building height regime is represented by: semi-basement, ground floor, other 5 levels and a technical room on top of the building. The building subdivision is composed of two staircases, located on building extremities, on East and West sides, connected with a corridor from which offices and laboratory rooms start. The building is oriented North-South and, excepting the semibasement and ground floor, an important part of North and South facades are realized by curtains walls, figure 1 . The constructive system of the building is realized by reinforced concrete and the exterior walls are made of Porotherm bricks insulated with expanded polystyrene EPS. The building cooling is realized by a chiller type CLINT, model 13010-P located on the building roof.

In 2015 the building has been modernized and a shading device composed of metallic blades was mounted on the South façade.

At the moment of the study the building was free all around (completely detached), so the received solar radiation wasn't shaded by the neighboring buildings.

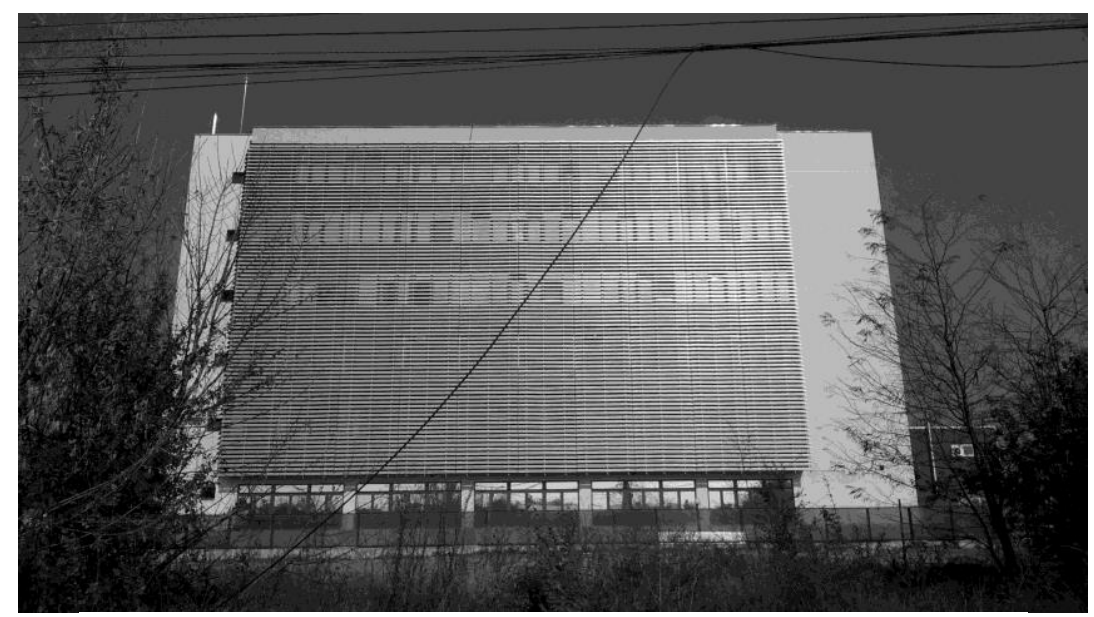

Fig. 1. INCD-ECOIND building - South facade 


\section{b. Shading devices}
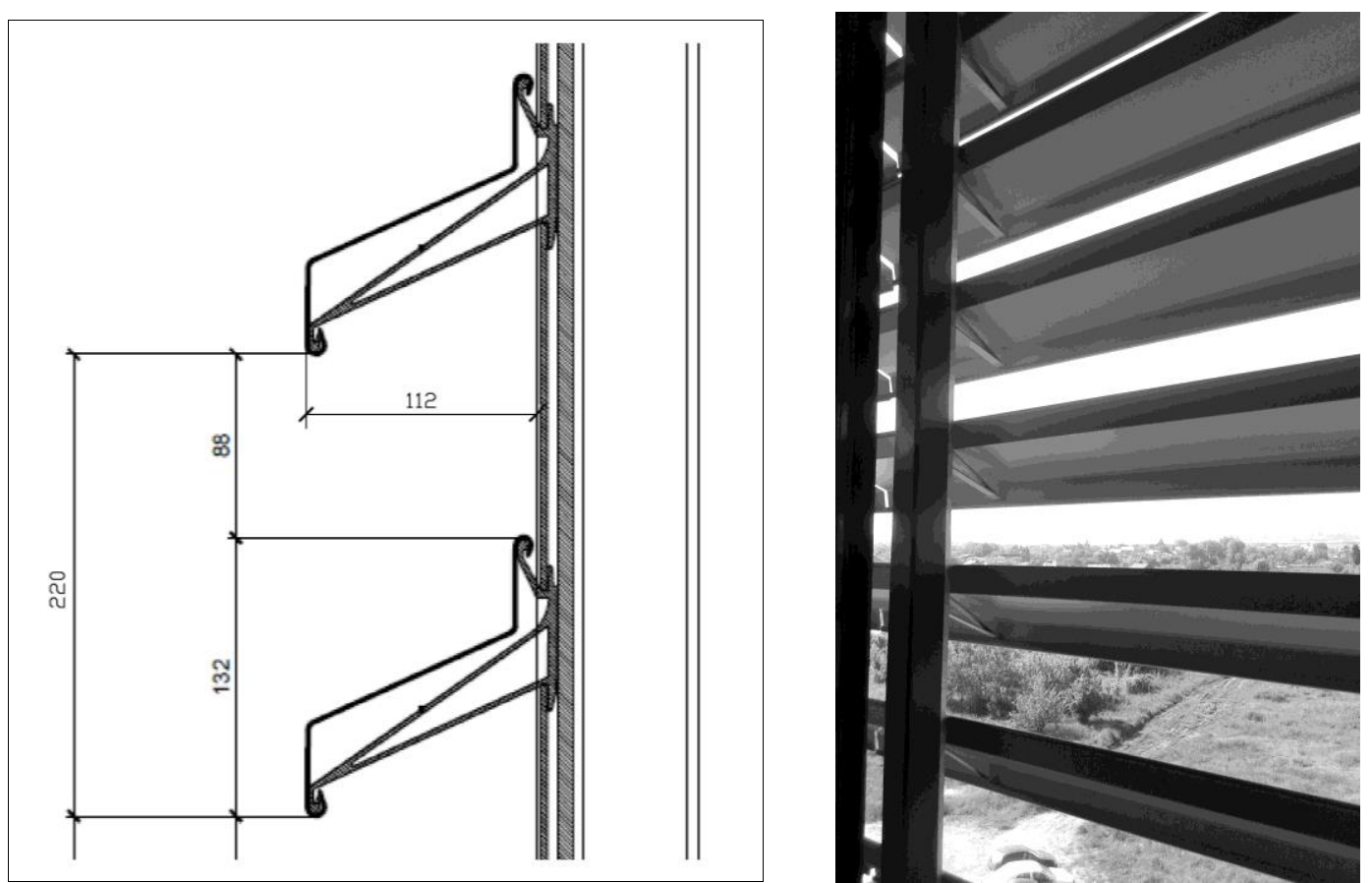

Fig. 2 Blades metalic system: a) transversal section, values in $\mathrm{mm}$; b) view from indoor

The metallic blades system located on South façade, result of building modernization, is over the curtain wall. The system can be seen in fig. 1, that represents an overview of the entire façade, and in fig. 2 at detailed level.

The blades system producer is Hunter Douglas Europe BV. They are fixed on a light metallic frame, connected to the building structure or to the vertical elements of the curtain wall. This kind of solution was chosen, on the one hand, because its mounting system is located only on the building exterior and thus didn't interfere with the working process in the building in the mounting period, and on the other hand, due to the fact that it is an exterior shading device and, as it is known to be more efficient than an interior one. The blades are positioned at a rather small distance, mounted at $220 \mathrm{~mm}$ from one another. The distance between blades extremities is of $88 \mathrm{~mm}$, as one can see in fig. 2 a).

\section{c. Shading calculation procedure}

In figure 3 a) it can be seen the plane where the observer is standing on Earth surface. It is named horizon plane and it is a flat plane tangent to the Earth's surface in point 0 . In order to describe Sun (or other star) position, the Horizon Coordinate system is defined. Thus, in fig. $3 \mathrm{~b}$ ), the observer plane is N-S-E-V diameter of the sphere. Azimuth (az) is the coordinate defining directions parallel to the horizon. It goes from 0 to $360^{\circ}$ starting with north $=0^{\circ}$ and increasing towards the East. Altitude (alt) is the coordinate defining directions above or below the horizon plane, how high an object is in the sky, fig. $3 \mathrm{~b}$ ).

In fig. 4 the South façade of the building and horizontal projection of the metallic blade are represented. In the shading calculation procedure the 
shading device could be assimilated with its horizontal projection, because it has the same effect in building shading, as can be seen in fig. 4 .
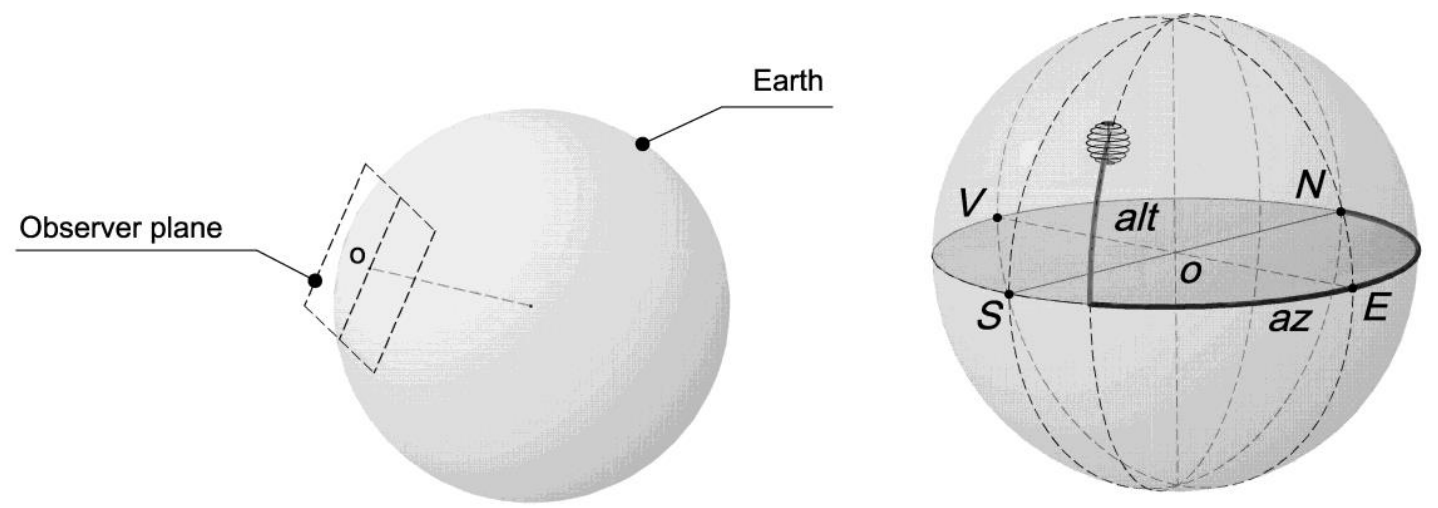

Fig. 3 a) Earth and the horizon plane; b) Azimuth (az) and altitude (alt) in the Horizon Coordinate system

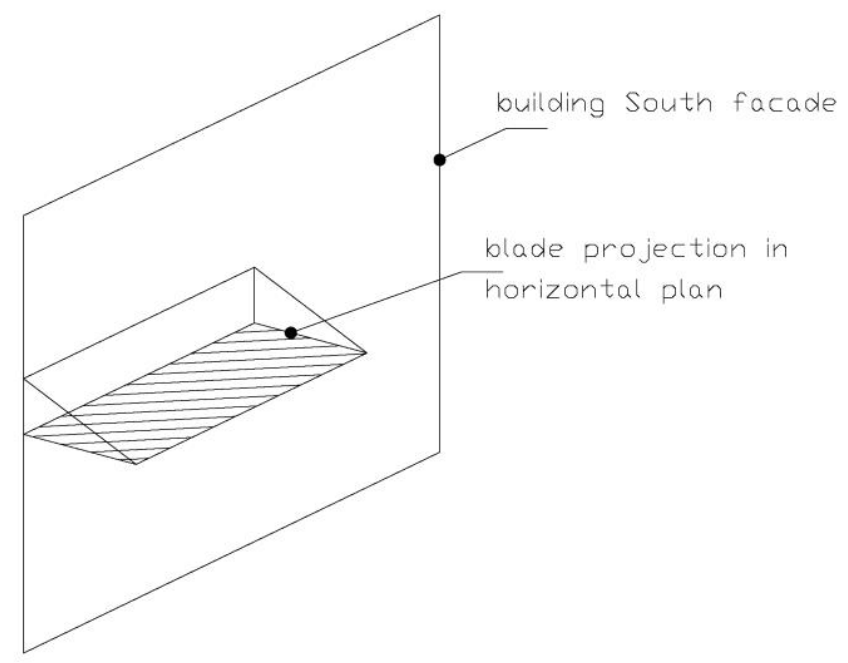

Fig. 4 South facade and the horizontal projection of the metallic blade

The South façade plan, that is perpendicular to the N-S plane, can be noticed in figure 5. For the observer, standing on Earth surface, in point 0 , the Sun position, located in a current plane has position established by azimuth (az) and altitude (alt) angles. In this case azimuth is measured relatively to South direction, but you will see in Table 1 the conversion from South to North direction. The same solar beam can be represented in the intersection point between current plane and horizontal blade projection plane. It is known that all solar beams at a moment of time reach the Earth after the same direction. Azimuth angle "az" can be found in the ABC triangle. This triangle represents the intersection of the horizontal projection of the metallic slat plane with the current Sun plane and the N-S plane. The " $m$ " distance can be expressed by " $h$ " (the distance from slat to wall as can be seen in figure 2 a), as one can see in equation 1 . The shading distance "d" can be computed from BCD triangle using equation 2.

\begin{tabular}{|l|l|}
\hline $\boldsymbol{m}=\boldsymbol{h} / \cos a z$ & (1) \\
\hline $\boldsymbol{d}=\boldsymbol{m} / \boldsymbol{t g}\left(90^{\circ}-\boldsymbol{a l t}\right)$ &
\end{tabular}




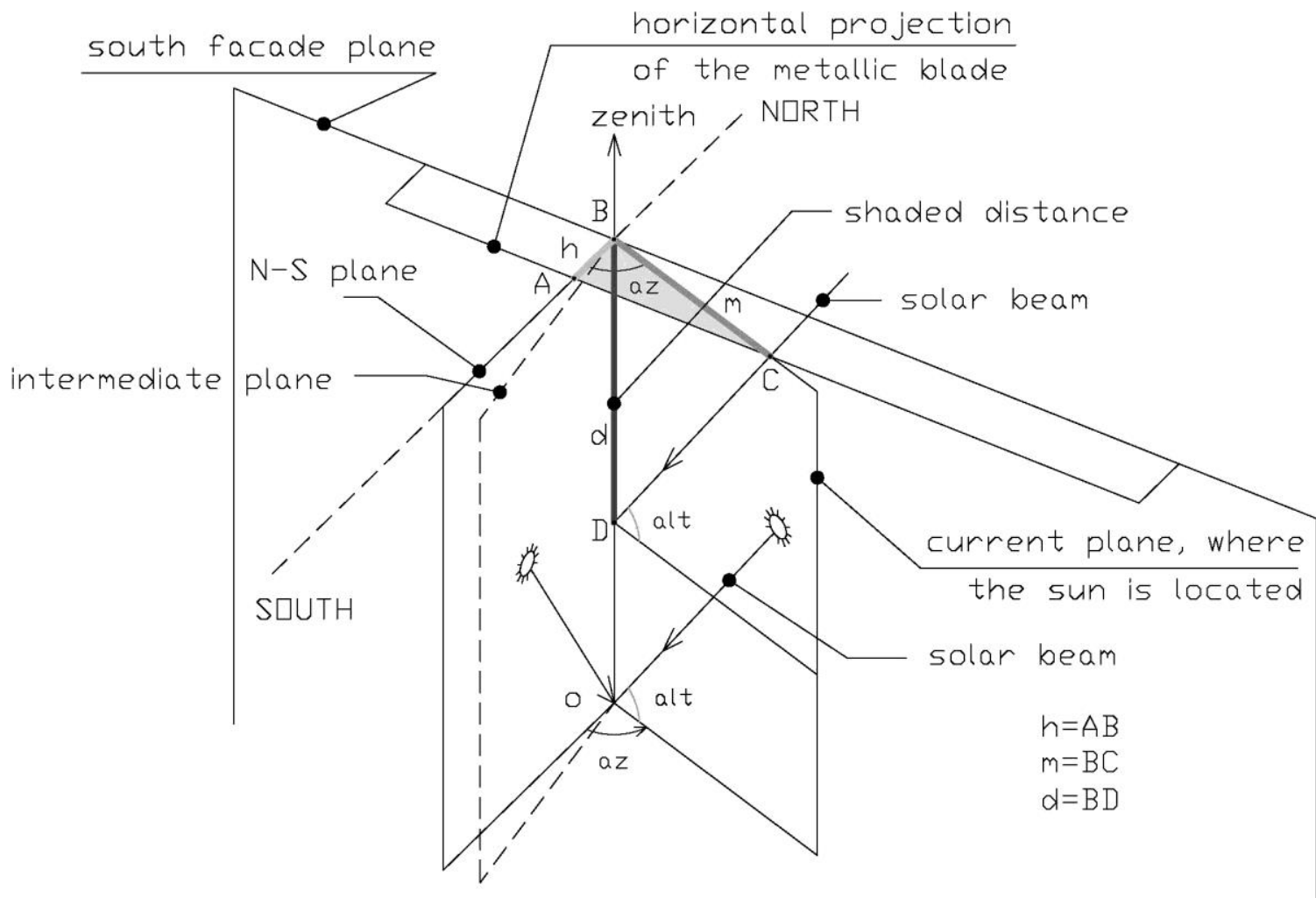

Fig. 5 Elements used in the shading distance calculation

The shading distance, expressed by " $\mathrm{h}$ " is presented in equation 3 and it results from equations 1 and 2 .

$$
\begin{array}{|l|l|}
\hline d=\frac{h}{\cos a z^{*} \boldsymbol{t g}\left(90^{\circ}-a l t\right)}=\frac{0.112}{\cos a z^{*} \boldsymbol{t g}\left(90^{\circ}-a l t\right)} & \text { (3) } \\
\hline
\end{array}
$$

\section{Results and Discussion}

The optimal distance in terms of building shading for mounting two blades aims to be determined. For this purpose, it is necessary to determine the minimum distance $\mathrm{d}$ for cooling period. The distance varies hour by hour so an hourly computation method is needed. The summer solstice is on June 21st and Sun position in the sky is symmetrical from this calendar data. A daily computation for all period is too laborious so three relevant values were chosen: April 21st, May 21st and June 21st. The calculation can be stopped on June 21 st because the results will be symmetrical to this data.

NOAA Solar Position Calculator [8] was used to obtain the hourly variation of the solar azimuth and altitude, on chosen days, for Bucharest. The used values were for year 2015 as a characteristic year was not available.

In the summer, Sun rises North from East and sets South from West. We study only the South façade shading and thus, the azimuth angles between 90 and 270 are of interest. In table 1 the computation for the hourly shading distance for May 21st is shown. For each hour its middle was considered: 5:30, 6:30 and so on. At the beginning and the end of the shaded period the middle of the interval between 
complete hour and the start or end hour of the lighting is considered, as can be seen in table 1.

Tab. 1 Hourly shading distances computed for May 21, 2015

May 21, 2015

\begin{tabular}{|r|r|r|r|r|r|r|r|r|r|}
\hline hour & $\begin{array}{c}\text { azimuth } \\
\text { North } \\
\text { [degree] }\end{array}$ & \multicolumn{1}{l}{$\begin{array}{l}\text { altitude } \\
\text { [degree] }\end{array}$} & hour & $\begin{array}{c}\text { azimuth } \\
\text { North } \\
\text { [degree] }\end{array}$ & $\begin{array}{c}\text { azimuth } \\
\text { South } \\
\text { [degree] }\end{array}$ & $\begin{array}{c}\text { altitude } \\
\text { [degree] }\end{array}$ & $\begin{array}{c}\text { azimuth } \\
\text { [rad] }\end{array}$ & $\begin{array}{c}\text { altitude } \\
\text { [rad] }\end{array}$ & $d$ [mm] \\
\hline $5: 30$ & 68.42 & 6.94 & & & & & & & \\
\hline $6: 30$ & 78.31 & 17.12 & & & & & & & \\
\hline $7: 30$ & 88.33 & 27.71 & $7: 50$ & 91.84 & 88.16 & 31.27 & 1.54 & 0.55 & 2118 \\
\hline $8: 30$ & 99.33 & 38.37 & $8: 30$ & 99.33 & 80.67 & 38.37 & 1.41 & 0.67 & 547 \\
\hline $9: 30$ & 112.67 & 48.64 & $9: 30$ & 112.67 & 67.33 & 48.64 & 1.18 & 0.85 & 330 \\
\hline $10: 30$ & 130.73 & 57.76 & $10: 30$ & 130.73 & 49.27 & 57.76 & 0.86 & 1.01 & 272 \\
\hline $11: 30$ & 156.88 & 64.14 & $11: 30$ & 156.88 & 23.12 & 64.14 & 0.40 & 1.12 & 251 \\
\hline $12: 30$ & 190.15 & 65.39 & $12: 30$ & 190.15 & -10.15 & 65.39 & -0.18 & 1.14 & 248 \\
\hline $13: 30$ & 219.91 & 60.8 & $13: 30$ & 219.91 & -39.91 & 60.80 & -0.70 & 1.06 & 261 \\
\hline $14: 30$ & 240.86 & 52.54 & $14: 30$ & 240.86 & -60.86 & 52.54 & -1.06 & 0.92 & 300 \\
\hline $15: 30$ & 255.75 & 42.61 & $15: 30$ & 255.75 & -75.75 & 42.61 & -1.32 & 0.74 & 419 \\
\hline $16: 30$ & 267.49 & 32.05 & $16: 22$ & 266.03 & -86.03 & 33.48 & -1.50 & 0.58 & 1070 \\
\hline $17: 30$ & 277.79 & 21.4 & & & & & & & \\
\hline $18: 30$ & 287.66 & 11.03 & & & & & & & \\
\hline
\end{tabular}

\begin{tabular}{|c|c|c|}
\hline $7: 40$ & 90.07 & 29.49 \\
\hline \multicolumn{3}{|c|}{ Middle of the interval 7:40 and 8:00 } \\
\hline $7: 50$ & 91.84 & 31.27 \\
\hline $16: 44$ & 269.98 & 29.56 \\
\hline \multicolumn{3}{|c|}{ Middle of the interval 16 and $16: 44$} \\
\hline $16: 22$ & 266.03 & 33.48 \\
\hline
\end{tabular}

Tab. 2 Hourly shading distances for April 21, May 21, and June 21, 2015

\begin{tabular}{|r|r|r|r|r|r|}
\hline \multicolumn{2}{|c|}{ April 21} & \multicolumn{2}{|c|}{ May 21} & \multicolumn{2}{c|}{ June 21 } \\
\hline \multicolumn{1}{|c|}{ hour } & $\mathrm{d}[\mathrm{mm}]$ & \multicolumn{1}{c|}{ hour } & $\mathrm{d}[\mathrm{mm}]$ & \multicolumn{1}{c|}{ hour } & $d[\mathrm{~mm}]$ \\
\hline & & & & & \\
\hline $7: 31$ & 515 & $7: 50: 00$ & 2118 & & \\
\hline $8: 30$ & 251 & $8: 30: 00$ & 547 & $8: 31: 00$ & 1011 \\
\hline $9: 30$ & 202 & $9: 30: 00$ & 330 & $9: 30: 00$ & 439 \\
\hline $10: 30$ & 184 & $10: 30: 00$ & 272 & $10: 30: 00$ & 333 \\
\hline $11: 30$ & 176 & $11: 30: 00$ & 251 & $11: 30: 00$ & 298 \\
\hline $12: 30$ & 175 & $12: 30: 00$ & 248 & $12: 30: 00$ & 291 \\
\hline $13: 30$ & 179 & $13: 30: 00$ & 261 & $13: 30: 00$ & 308 \\
\hline $14: 30$ & 192 & $14: 30: 00$ & 300 & $14: 30: 00$ & 364 \\
\hline $15: 30$ & 222 & $15: 30: 00$ & 419 & $15: 30: 00$ & 553 \\
\hline $16: 30$ & 328 & $16: 22: 00$ & 1070 & $16: 16: 00$ & 1672 \\
\hline $17: 12$ & 1042 & & & & \\
\hline
\end{tabular}

The same computation was done for April 21st and May 21st and the data is systemized in table 2 . The possible distance to be shaded (distance between blades extremities) is of $88 \mathrm{~mm}$, see figure $2 \mathrm{a}$ ). In table 2 it is noticed that all computed 
distances are bigger than $88 \mathrm{~mm}$. In conclusion, it can be said that for all summer period the building South façade is completely shaded.

As you can see in table 2, the minimum distance between two blades is of $175 \mathrm{~mm}$. It is normal that the smallest distances are obtained for April, when the sun position in the sky is lower.

The cooling energy load decreasing realized by the shading devices was determined. For cooling period the glazed South facade of the building was considered shaded completely. The computation method used is a monthly one, specific to Romanian certification procedure. The calculation method is not the purpose of this paper, it is intended only to present the shading effect on building energy needed for cooling. The results are presented in table 3.

Tab. 3 Annual energy needed for cooling for shadeless and shaded building

\begin{tabular}{|c|c|c|}
\hline & annual total [kWh] & specific annual total \\
\hline shadeless building & 39226 & 16.24 \\
\hline shaded building & 27425 & 11.35 \\
\hline
\end{tabular}

\section{Conclusions}

In this paper, the influence of the shading devices on the building envelope was studied. For this purpose, an office and laboratory building provided with a fixed metallic blades system, mounted on the South façade was chosen. The vertical shaded distance for relevant days in cooling period was computed hour by hour. The conclusion is that for a distance of $88 \mathrm{~mm}$ between the extremities of two consecutive blades it is realized a full shading of the glazing area of the South facade in the cooling period. Using the same computation, a minimum distance of $175 \mathrm{~mm}$ between blades for which full shading is realized was found. But, for a precise estimation, the cooling period is better to be established. This cannot be realized within a monthly method of calculation, so a covering distance of $150 \mathrm{~mm}$ between two blades is recommended. A smaller distance makes a full shading in the summer period but it presents two disadvantages: the solar gains, useful in winter could be lost and the cost for metallic blades increases.

From table 3 it is observed a 30\% energy need for cooling reduction if the shading system is used. Besides this, the thermal comfort increases because the direct solar radiation doesn't enter by the glazing area in the building and so the mean radiant temperature decreases.

\section{References}

[1]. DIRECTIVE 2010/31/EU OF THE EUROPEAN PARLIAMENT AND OF THE COUNCIL of 19 May 2010 on the energy performance of buildings, (2010), URL: http://eurlex.europa.eu/legal-

content/EN/ALL/;ELX_SESSIONID=FZMjThLLzfxmmMCQGp2Y1s2d3TjwtD8QS3pqdkhXZb wqGwlgY9KN!2064651424?uri=CELEX:32010L0031, [accessed: March 2015];

[2]. DIRECTIVE 2012/27/EU OF THE EUROPEAN PARLIAMENT AND OF THE COUNCIL of 25 October 2012 on energy efficiency, (2012), URL: http://eur-lex.europa.eu/legalcontent/EN/TXT/?qid=1399375464230\&uri=CELEX:32012L0027, [accessed: March 2015]; 
[3]. Y.B. Yoon, D.S. Kim, K.H. Lee, (2014), Detailed heat balance analysis of the thermal load variations depending on the blind location and glazing type, Energy and Buildings, 75, pp. 8495, DOI: 10.1016/j.enbuild.2014.02.002;

[4]. M.-S. Fahrion, S. Horn, B. Weller, (2015), Glass Facades of the Eastmodernism Construction and Climate-Change-Adaptation [Glasfassaden der Ost-Moderne - Konstruktion und Klimaanpassung] Bautechnik, 92 (12), pp. 815-824, DOI: 10.1002/bate.201500016;

[5]. Köpeen-Geiger, (2014), World Map of the Köppen-Geiger Climate Classification, URL: http://en.wikipedia.org/wiki/File:Europe_Koppen_Map.png, [accessed: September 2016];

[6]. Badescu V., Rotar N., Udrea I., (2015), Considerations concerning the feasibility of the German Passivhaus concept in Southern Hemisphere, Energy Efficiency, ISSN 1570-646X, DOI 10.1007/s12053-015-9332-8, Voulme 08, Issue 01, publicat online: http://link.springer.com/article/10.1007/s12053-015-9332-8;

[7]. I. Udrea, (2015) Analiza teoretică și experimentală a confortului în Clădiri Pasive (Theoretical and experimental analysis of comfort in Passive Houses), (PhD Thesis), UPB, Fac. Inginerie Mecanica si Mecatronica;

[8]. NOAA, Solar Position Calculator, U.S. Department of Commerce National Oceanic \& Atmospheric Administration, NOAA Research, Global radiation Group, http://www.esrl.noaa.gov/gmd/grad/solcalc/; 